\section{Adherence to Photographic Standards: A Review of ASPS and ASAPS Member Surgeons' Websites}

\section{Abstract}

Background: To evaluate the adherence of images on plastic surgeons' websites with the photographic standards established in 2006 by the American Society of Plastic Surgeons (ASPS) and the Plastic Surgery Foundation (PSF).

Methods and findings: The membership rosters of the ASPS and the American Society for Aesthetic Plastic Surgery (ASAPS) were combined, and a random selection of $10 \%$ of these members was chosen for evaluation. Surgeons from the United States and Canada were included. Surgeons who were international members, who did not have websites or who had websites but did not have the images of interest were excluded. A total of 122 members of the $10 \%$ sample met the criteria. Breast augmentation, abdominoplasty and rhinoplasty images were reviewed and evaluated for focus, framing, positioning, presence of uniform background, absence of shadow, absence of clothing, absence of jewelry, use of photo garments, and exposure.

Results: None of the websites evaluated universally adhered to the photographic standards, and the average was $66.3 \%$. The average adherence was $76.2-77.0 \%$, 64.6-63.8\% and 57.6-58.2\% for breast, face and abdominal images pre and postoperative respectively. Breast postoperative compliance was significantly improved for correct positioning, focus, and no cast shadow. Facial compliance was significantly improved for good background postoperatively whereas makeup compliance was higher preoperatively, and abdominal compliance was significantly improved for postoperative correct position although preoperative photo garments compliance was higher.

Conclusion: Sixty-six percent of images on ASPS and ASAPS plastic surgeons' websites were adherent to the photographic standards, and pre and post adherence were similar.

Keywords: Photographic standards; Framing; Patient positioning

Abbreviations: ASAPS: American Society for Aesthetic Plastic Surgery; ASPS: American Society of Plastic Surgeons; PSF: Plastic Surgery Foundation

\author{
Sanniec KJ', Velazco CS ${ }^{2}$, \\ Macias LH $^{3}$, Zuhlke TA2, \\ Casey III WJ', Leighton WD ${ }^{3}$, \\ Mahabir RC ${ }^{3}$ and \\ Rebecca $\mathrm{AM}^{3}$
}

1 Department of Plastic Surgery, UT Southwestern, Dallas, TX, USA

2 Division of General Surgery, Mayo Clinic in Arizona, Phoenix, Ariz, USA

3 Division of Plastic and Reconstructive Surgery, Mayo Clinic in Arizona, Phoenix, Ariz, USA

\section{Corresponding author: Rebecca AM}

झ rebecca.alanna@mayo.edu

Mayo Clinic Hospital, 5777 East Mayo Blvd, Phoenix, AZ 85054, USA.

Tel: 480-342-2899

Citation: Sanniec KJ, Velazco CS, Macias LH, et al. Adherence to Photographic Standards: A Review of ASPS and ASAPS Member Surgeons' Websites. J Aesthet Reconstr Surg. 2016, 2:2.

Received: April 20, 2016; Accepted: June 13, 2016; Published: June 22, 2016

\section{Introduction}

Photographic documentation is essential in plastic surgery. Numerous articles regarding photographic standards have been published with many of the more recent examples found in the facial plastic surgery literature [1-5]. In order to assist plastic surgeons in professionalism, privacy, operative planning, and documentation of pertinent anatomy without distortion or distraction, the American Society of Plastic Surgeons and the Plastic Surgery Educational Foundation (now known as Plastic Surgery Foundation (PSF) and henceforth will be referred to as PSF) (ASPS/PSF) published The Photographic Standards in Plastic Surgery in 2006 [6]. Many members of ASPS and the ASAPS (American Society for Aesthetic Plastic Surgery) host public websites where "before and after" images of patients are posted. These websites are often a prospective patient's first exposure 
not only to a particular surgeon, but also to the discipline of plastic and reconstructive surgery. These images are therefore very important in shaping public perspective [7-9]. We examined images posted on ASPS and ASAPS member surgeons' websites for adherence to ASPS/PSF standards for breast, abdominal, and close up facial photo series.

\section{Methods}

After IRB approval, random selection of ten percent $(n=260)$ of United States and Canadian member surgeons with ASPS and ASAPS membership was performed. We excluded international members, members without a website, and members whose websites did not contain images of breast augmentation, abdominoplasty, and/or rhinoplasty. A total of 122 (4.7\%) ASAPS/ ASPS member websites of the $10 \%$ sample met the inclusion criteria.

All websites were de-identified prior to evaluation. The standard views were those described in The Photographic Standards in Plastic Surgery for breast augmentation, abdominoplasty and rhinoplasty on Table 1. Images were evaluated by one of three independent trainees (KS, LM, TZ). The first and last set of "before and after" images on each website were compared with the standard views and evaluated for focus, framing, proper positioning, use of a uniform background, presence of a cast shadow, the absence of clothing and jewelry, proper exposure and use of photo garments. A uniform background was defined as any single color background surface. Images were categorized as overexposed when there was either loss of highlight detail or when parts of the image were effectively all white or washed out. Images were considered underexposed when the important dark areas were obscured or indistinguishable from the background. Excess makeup was recorded if the makeup was distracting to the reviewer. Results were entered into a database using Excel (Microsoft Corporation, Redmond, Washington). Statistical analysis was completed using paired t-test.

\section{Results}

A total of 2180 individual images (921 breast images, 432 closeup face images, and 827 abdomen images) were reviewed. Of the 122 surgeons' websites evaluated, there was at least one image on each site that did not meet the ASPS/PSF standard guidelines. Adherence rates varied widely ranging from $12-90 \%$ as seen on Figure 1 and improper framing was a consistent issue across all three anatomic areas. Tables 2-4 provide the details for the breast, abdominal and facial image reviews. Pre- and postoperative adherence rates demonstrated consistency with the exception of photo garments in facial series and positioning in abdominal series. Table 5 provides statistical analysis between pre- and postoperative adherence rates. For breast images postoperative compliance was improved for correct positioning $(p=0.0342)$, focus $(p=0.0178)$, and no cast shadow $(p=0.037)$. Facial image review showed compliance was only improved for good background ( $p=0.0315)$ postoperatively; whereas makeup compliance was higher preoperatively $(p=0.0002)$. Abdominal image review demonstrated improved postoperative compliance
Table 1 Photographic standards.

\begin{tabular}{|c|c|}
\hline \multicolumn{2}{|l|}{ Breast } \\
\hline \multirow{2}{*}{ Patient Preparation } & Patient disrobed above the waist \\
\hline & All visible jewelry removed \\
\hline \multirow{3}{*}{ Patient Positioning } & $\begin{array}{l}\text { Patient standing comfortably erect with arms } \\
\text { at sides }\end{array}$ \\
\hline & Feet aligned \\
\hline & $\begin{array}{l}\text { Distal arm should be moved slightly back on } \\
\text { oblique views }\end{array}$ \\
\hline \multirow{4}{*}{ Framing } & Position clavicles at top of frame \\
\hline & $\begin{array}{l}\text { Center torso horizontally for frontal and } \\
\text { oblique views }\end{array}$ \\
\hline & $\begin{array}{l}\text { Center mass of proximal breast horizontally for } \\
\text { lateral views }\end{array}$ \\
\hline & $\begin{array}{l}\text { Distal breast should not be visible in lateral } \\
\text { view }\end{array}$ \\
\hline \multicolumn{2}{|l|}{ Abdomen } \\
\hline \multirow{2}{*}{ Patient Preparation } & Remove gown completely \\
\hline & Patient should wear a photo garment \\
\hline \multirow[t]{2}{*}{ Patient Positioning } & $\begin{array}{l}\text { Patient standing comfortable erect with arms } \\
\text { folded above breasts }\end{array}$ \\
\hline & Feet aligned \\
\hline \multirow{2}{*}{ Framing } & Position inframammary fold at top of frame \\
\hline & Center torso horizontally \\
\hline \multicolumn{2}{|l|}{ Close Up Face } \\
\hline \multirow{4}{*}{ Patient Preparation } & $\begin{array}{l}\text { Pull hair off face and behind ears (Use black } \\
\text { headband or small clips that hold hair without } \\
\text { pulling) }\end{array}$ \\
\hline & Remove jewelry and eyeglasses \\
\hline & Remove heavy makeup \\
\hline & Cover shirt collar with black drape \\
\hline \multirow{3}{*}{ Patient Positioning } & $\begin{array}{l}\text { Seat patient on a stool adjusted to a } \\
\text { comfortable height and placed at center of a } \\
\text { tape mark }\end{array}$ \\
\hline & $\begin{array}{l}\text { Have patient sit up straight with feet on either } \\
\text { side of the tape mark }\end{array}$ \\
\hline & $\begin{array}{l}\text { Patient should rotate entire body for oblique } \\
\text { and lateral views }\end{array}$ \\
\hline \multirow{2}{*}{ Framing } & Place eyebrows at top of frame \\
\hline & Center nose horizontally in all views \\
\hline
\end{tabular}

for correct position $(p=0.0004)$, although there was higher preoperative compliance with photo garments $(p=0.0308)$.

\section{Discussion}

In our random sample of websites there was a disparity from the ASPS/PSF published standards. This study was unable to resolve whether these variations were a result of surgeon preference, different protocols, flawed photographic technique, or patient positioning instructions. In the future, it may be of interest to examine provider websites with photo recognition software to see if compliant photographs were industry provided vs. the practitioner taking photographs.

The most common deviation from the ASPS/PSF guidelines 


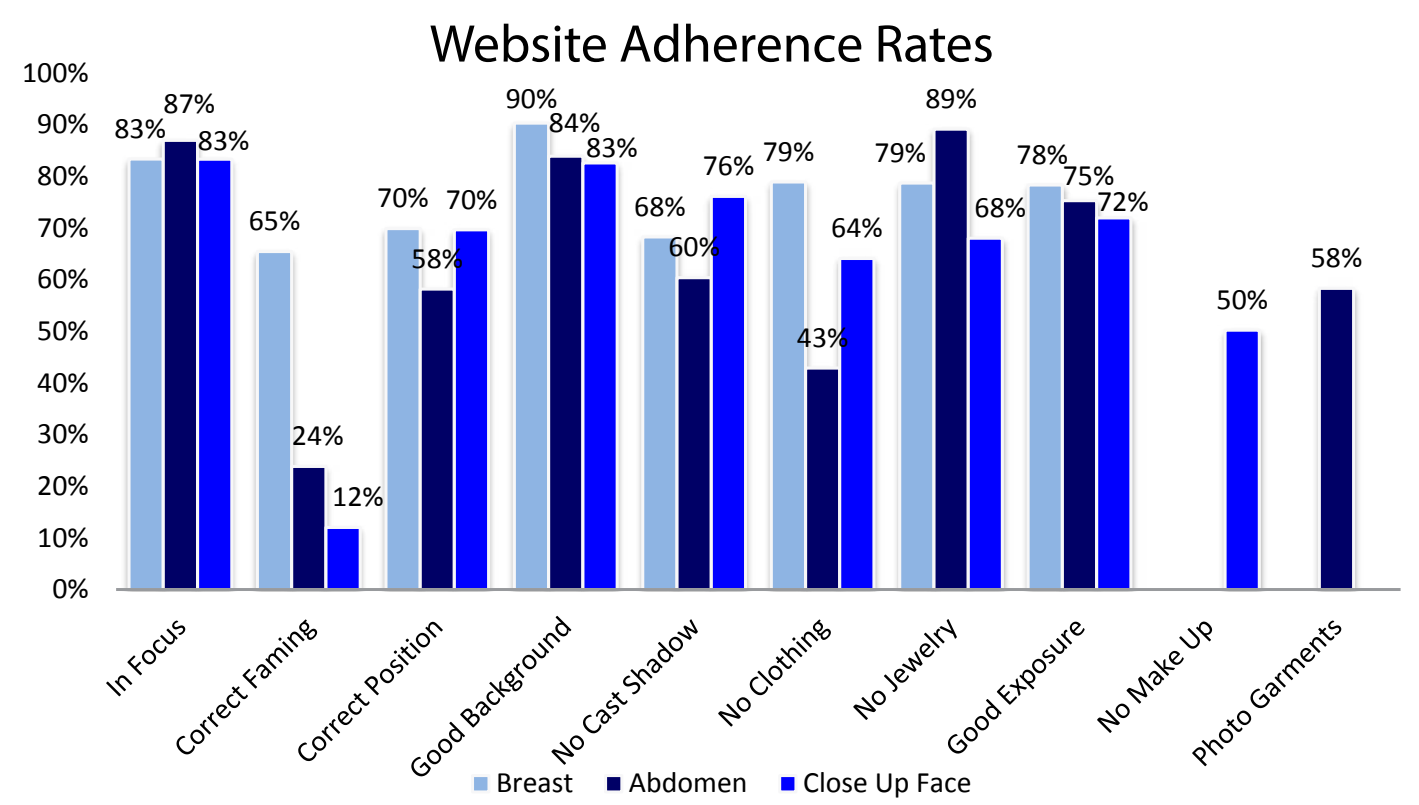

Figure 1 Website adherence rates by member surgeons of American Society of Plastic Surgeons (ASPS) and the American Society for Aesthetic Plastic Surgery (ASAPS).

Table 2 Review of breast image adherence.

\begin{tabular}{|c|c|c|c|}
\hline Adherence to Standard & Total $n(\%)$ & Lower & Upper \\
\hline In Focus & $763(83 \%)$ & $81 \%$ & $86 \%$ \\
\hline Correct Framing & $603(65 \%)$ & $62 \%$ & $69 \%$ \\
\hline Correct Positioning & $643(70 \%)$ & $67 \%$ & $73 \%$ \\
\hline Uniform Background & $832(90 \%)$ & $88 \%$ & $92 \%$ \\
\hline No Cast Shadow & $628(68 \%)$ & $65 \%$ & $71 \%$ \\
\hline No Clothing Visible & $727(79 \%)$ & $76 \%$ & $82 \%$ \\
\hline Absence of Jewelry & $724(79 \%)$ & $76 \%$ & $81 \%$ \\
\hline Good Exposure & $720(78 \%)$ & $75 \%$ & $81 \%$ \\
\hline Excess Makeup & NA & NA & NA \\
\hline Photo Garment Present & NA & NA & NA \\
\hline Nude & NA & NA & NA \\
\hline Total Images & 921 & - & - \\
\hline
\end{tabular}

Table 3 Review of abdominal image adherence.

\begin{tabular}{|c|c|c|c|}
\hline Adherence to Standard & Total $n(\%)$ & \multicolumn{2}{c|}{$95 \%$ Confidence Interval } \\
\hline In Focus & $715(87 \%)$ & $85 \%$ & Upper \\
\hline Correct Framing & $196(24 \%)$ & $21 \%$ & $29 \%$ \\
\hline Correct Positioning & $479(58 \%)$ & $58 \%$ & $62 \%$ \\
\hline Uniform Background & $695(84 \%)$ & $81 \%$ & $86 \%$ \\
\hline No Cast Shadow & $496(60 \%)$ & $57 \%$ & $46 \%$ \\
\hline No Clothing Visible & $353(43 \%)$ & $40 \%$ & $91 \%$ \\
\hline Absence of Jewelry & $733(89 \%)$ & $87 \%$ & $78 \%$ \\
\hline Good Exposure & $620(75 \%)$ & $72 \%$ & NA \\
\hline Excess Makeup & NA & $40 \%$ & \\
\hline Photo Garment Present & $355(43 \%)$ & $13 \%$ & $18 \%$ \\
\hline Nude & $125(15 \%)$ & - & - \\
\hline
\end{tabular}


Table 4 Review of close up face image adherence.

\begin{tabular}{|c|c|c|c|}
\hline Adherence to Standard & Total $n(\%)$ & \multicolumn{2}{c|}{$95 \%$ Confidence Interval } \\
\hline In Focus & $360(83 \%)$ & $79 \%$ & Upper \\
\hline Correct Framing & $52(12 \%)$ & $9 \%$ & $15 \%$ \\
\hline Correct Positioning & $301(70 \%)$ & $65 \%$ & $74 \%$ \\
\hline Uniform Background & $357(83 \%)$ & $79 \%$ & $86 \%$ \\
\hline No Cast Shadow & $329(76 \%)$ & $72 \%$ & $72 \%$ \\
\hline No Clothing Visible & $277(64 \%)$ & $63 \%$ & $69 \%$ \\
\hline Absence of Jewelry & $294(68 \%)$ & $59 \%$ & $76 \%$ \\
\hline Good Exposure & $311(72 \%)$ & $67 \%$ & 5 \\
\hline Excess Makeup & $216(50 \%)$ & $45 \%$ & \\
\hline Photo Garment Present & NA & NA & \\
\hline Nude & NA & NA & NA \\
\hline Total Images & 432 & - & - \\
\hline
\end{tabular}

Table 5 Preoperative and postoperative adherence.

\begin{tabular}{|c|c|c|c|c|c|c|c|c|c|c|}
\hline & \multirow{2}{*}{ Category/Standard } & \multicolumn{4}{|c|}{ Preoperative } & \multicolumn{4}{|c|}{ Postoperative } & \multirow{2}{*}{ P-value* } \\
\hline & & $\mathbf{N}$ & Mean & SD & Median & $\mathbf{N}$ & Mean & SD & Median & \\
\hline \multirow{8}{*}{$\begin{array}{l}\text { Breast image (oblique } \\
+ \text { lateral + frontal) }\end{array}$} & Correct Framing & 122 & 2.41 & 1.54 & 2 & 122 & 2.53 & 1.62 & 3 & 0.1243 \\
\hline & Correct Position & 122 & 2.55 & 1.51 & 2 & 122 & 2.72 & 1.46 & 3 & 0.0342 \\
\hline & Good Background & 122 & 3.41 & 1.61 & 4 & 122 & 3.41 & 1.59 & 4 & 1.0000 \\
\hline & Good Exposure & 122 & 2.96 & 1.6 & 3 & 122 & 2.94 & 1.78 & 3 & 0.8795 \\
\hline & In Focus & 122 & 3.07 & 1.65 & 3 & 122 & 3.23 & 1.58 & 4 & 0.0178 \\
\hline & No Cast Shadow & 122 & 2.67 & 1.53 & 2 & 122 & 2.48 & 1.39 & 2 & 0.0137 \\
\hline & No Clothing & 122 & 2.99 & 1.63 & 3 & 122 & 2.97 & 1.6 & 3 & 0.7596 \\
\hline & No Jewelry & 122 & 2.98 & 1.43 & 3 & 122 & 2.96 & 1.49 & 3 & 0.8719 \\
\hline \multirow{9}{*}{$\begin{array}{c}\text { Face image (oblique + } \\
\text { lateral + frontal) }\end{array}$} & Correct Framing & 69 & 0.38 & 0.89 & 0 & 69 & 0.38 & 0.81 & 0 & 1.0000 \\
\hline & Correct Position & 69 & 2.22 & 1.44 & 2 & 69 & 2.14 & 1.28 & 2 & 0.539 \\
\hline & Good Background & 69 & 2.49 & 1.61 & 2 & 69 & 2.68 & 1.44 & 3 & 0.0315 \\
\hline & Good Exposure & 69 & 2.25 & 1.52 & 2 & 69 & 2.26 & 1.5 & 2 & 0.9301 \\
\hline & In Focus & 69 & 2.58 & 1.54 & 3 & 69 & 2.64 & 1.53 & 3 & 0.5675 \\
\hline & No Cast Shadow & 69 & 2.35 & 1.34 & 2 & 69 & 2.42 & 1.34 & 2 & 0.2543 \\
\hline & No Clothing & 69 & 1.96 & 1.19 & 2 & 69 & 2.06 & 1.17 & 2 & 0.3576 \\
\hline & No Jewelry & 69 & 2.12 & 1.46 & 2 & 69 & 2.14 & 1.41 & 2 & 0.8249 \\
\hline & No Make Up & 69 & 1.88 & 1.57 & 2 & 69 & 1.26 & 1.21 & 1 & 0.0002 \\
\hline \multirow{10}{*}{$\begin{array}{l}\text { Abdominal image } \\
\text { (oblique + lateral + } \\
\text { frontal) }\end{array}$} & Correct Framing & 113 & 0.92 & 1.21 & 0 & 113 & 0.82 & 1.1 & 0 & 0.2609 \\
\hline & Correct Position & 113 & 1.95 & 1.71 & 2 & 113 & 2.3 & 1.68 & 2 & 0.0004 \\
\hline & Good Background & 113 & 3.06 & 1.77 & 3 & 113 & 3.06 & 1.71 & 3 & 1.0000 \\
\hline & Good Exposure & 113 & 2.66 & 1.7 & 3 & 113 & 2.83 & 1.68 & 3 & 0.1588 \\
\hline & In Focus & 113 & 3.15 & 1.47 & 3 & 113 & 3.19 & 1.48 & 3 & 0.5375 \\
\hline & No Cast Shadow & 113 & 2.24 & 1.51 & 2 & 113 & 2.17 & 1.48 & 2 & 0.4307 \\
\hline & No Clothing & 113 & 1.55 & 1.61 & 1 & 113 & 1.58 & 1.65 & 1 & 0.7591 \\
\hline & No Jewelry & 113 & 3.31 & 1.38 & 3 & 113 & 3.19 & 1.48 & 3 & 0.1788 \\
\hline & Nude & 113 & 0.54 & 1.17 & 0 & 113 & 0.57 & 1.2 & 0 & 0.6331 \\
\hline & Photo Garments & 113 & 1.68 & 1.87 & 1 & 113 & 1.46 & 1.83 & 0 & 0.0308 \\
\hline
\end{tabular}

*Paired t-test: $\mathrm{P}<0.05$ is significant

encountered was in framing the photograph. Only $12 \%$ of facial, $24 \%$ of abdomen, and $65 \%$ of breast images were framed correctly. Most of the rhinoplasty before and after images was not framed or cropped close enough and showed too much of the face. Of the abdominal images the inframammary fold was either not visible in the top of the frame or too much of the breasts were included. The breast images were either framed too high, showing the chin, or too low, not showing the clavicles. Many images were clearly framed without a standard framing method; others were simply framed based on preference. Historically, a 
variety of standards have been proposed and taught in training; therefore, it was not surprising that there were images not conforming to the ASPS/PSF standards [10-16].

The next most common divergence from the guideline was in patient positioning. The patients in the abdominal images were less likely to be positioned properly ( $58 \%$ correct); whereas the breast and face patients were slightly more likely to be positioned as per the ASPS/PSF standards (70\%). However, on comparison between pre- and postoperative abdominal and breast positioning, we report statistical differences which may bias surgical outcome. The most common error noted in the positioning of the abdomen pictures was having the arms visible in the photograph. The best position for the arms is to be raised superiorly, out of the frame, and holding the breasts up and out of the frame, if necessary, demonstrating the inframammary folds. The most common error in breast patient positioning was in the oblique view with visibility of the arm furthest from the photographer.

For the close-up face images, positioning deviations were noted in bird's eye views and in failure to pull the hair back and out of the way. Use of hair clips or pins in order to place hair out of the way, and exposing the entire forehead, neck and ears is extremely helpful. Of note, the ASPS/PSF guideline does not discuss the patient's Frankfort horizontal line. Other guidelines have cited this as important for standardizing the tilt of the head $[17,18]$. Remi et al. demonstrated that even small deviations in patient positioning in facial photography can lead to significant deviations from photo documentary standards, leading to photographic faults [19]. Specifically, patient positioning and angles of photography can lead to a "photographic neck lift" or "rhinoplasty" distorting perceived outcomes following surgery $[19,20]$. The inconsistencies of preoperative and postoperative compliance of good background and no makeup in our study may also provide observer bias for postoperative outcomes. When ASPS revisits the publication, consideration could be given to including the use of the Frankfort horizontal line in the photographic standards.

The presence of a shadow is preventable with appropriate lighting. A straightforward method is to use a dual lighting source placed at 45-degree angles from the patient. Even then, faint shadows may still be appreciated. A small flash illuminating the background will eliminate shadows completely $[2,12,18]$. Some have advocated using a black background in order to eliminate the cast shadow, but this is not necessary with appropriate lighting. Black backgrounds can make it difficult to distinguish the patient with darker complexions and hair from the background. Most standards agree that a consistent color background should be used, with most advocating a blue color. These can vary from a felt background to a wall or wide door painted with flat paint, or a traditional, even-colored studio backdrop [12, 18].

A study by Lau et al. found that most patients consider medical photography acceptable, especially if the images are de-identified (patient not recognizable) [10]. The removal of jewelry not only makes the photo appear more professional and less distracting, but it also helps protect patient confidentiality. Jewelry was noted in $11 \%$ of patients on the wrists or hands and was visible due to inappropriate positioning; the only exception to this was occasional umbilical jewelry being visualized.

Of particular relevance to facial images is the use of makeup. Our evaluation of presence of make-up was subjective, as we noted when the makeup appeared to be "heavy" or distracting. Ideally, the patient would be photographed with no visible makeup. In practice this is difficult as many patients come to postoperative appointments with makeup already applied and are unwilling or unprepared to remove and reapply their make-up. Despite instructing patients to come to appointments without makeup applied, adherence remains an issue. Nonetheless, every effort should be taken to have the patient remove make-up prior to photographic documentation. Similarly, Riml et al. found that in one third of photographs published in three major plastic and reconstructive journals demonstrated patients wearing makeup [19]. We found that patients' photographs were likely to adhere preoperatively to no makeup than postoperatively, again influencing surgical outcome.

Patient's personal clothing is seen in many of the images, including personal undergarments in body images, pants or skirts in breast images and shirts not covered in facial photography. In addition to making the images look less professional, the clothing also increases the likelihood of being able to identify a patient. Differences in the clothing, especially undergarments, worn on the different days complicates the comparison of the before and after images. Some members have used nude patients and posted them with exposed genitalia, while others have superimposed a blackout of the area. Although the completely nude photo is the most desirable for comparison of before and after body images, the use of photo undergarments helps with standardizing the exposed areas while maintaining some modesty for the patient.

Exposure is a result of ambient light (light on the subject) being reflected to the digital sensor of the camera. Over- or underexposure may be due to too much light from a flash, lack of use of a flash or inappropriate setting on the camera for the available light. Thanks to advancements in digital photography, today's plastic surgeon cannot claim naivety and should be able to get consistent exposures in an office setting. In the literature there are numerous papers that have discussed how to obtain consistent images. These vary from simple office set-ups to near studio-style arrangements. Some attention to detail and a small investment of time and money will lead to professional, quality, standardized images that we should strive to obtain.

We believe that adherence to the published photographic standards would help to distinguish ASPS/ASAPS member plastic surgeons, promote professionalism, reduce errors, and provide appropriate documentation. Accessibility to photographic standards and guidelines should be facilitated by the societies, but it is incumbent on plastic surgeons to continually update themselves on photographic standards, review their websites, and strive for adherence with those standards. Adhering to standardized photographic guidelines would allow surgeons to critically analyze their surgical outcome measures (aesthetic results), review results (quality assurance) and compare outcomes 
(research). The authors encourage surgeons to both review and adopt the published standards for their individual websites.

\section{Conclusion}

Sixty-six percent of images on ASPS and ASAPS plastic surgeons' websites were adherent to the ASPS/PSF photographic standards and pre and post adherence was similar. Adherence to guidelines allow for consistent images that facilitate documentation and critique of a surgeon's outcomes.

\section{Conflicts of Interest}

The authors have no conflicts of interest to disclose. 


\section{References}

1 Zarem HA (1984) Standards of photography. Plast Reconstr Surg 74: 137-146.

2 Persichetti P, Simone P, Langella M, Marangi GF, Carusi C (2007) Digital photography in plastic surgery: how to achieve reasonable standardization outside a photographic studio. Aesthetic Plast Surg 31: 194-200.

3 Di Bernardo BE, Adams RL, Krause J, Fiorillo MA, Gheradini G (1998) Photographic standards in plastic surgery. Plast Reconstr Surg 102 559-568.

4 Becker DG, Tardy MEJ (1999) Standardized photography in facial plastic surgery: pearls and pitfalls. Facial Plast Surg 15: 93-99.

5 Becker DG (2006) Website for rhinoplasty and facial plastic surgery. Facial Plast Surg 22: 70-74.

6 ASPS/PSEF (2006) The Photographic Standards in Plastic Surgery.

7 Losken A, Burke R, Elliott LF, Carlson GW (2005) Infonomics and breast reconstruction: are patients using the internet? Ann Plast Surg 54: 247-250.

8 Szychta P, Zielinski T, Rykala J, Kruk-Jeromin J (2011) The internet as a source of information for patients prior to rhinoplasty. Clin Exp Otorhinolaryngol 4: 131-136.

9 Hamilton III GS, Carrithers JS, Karnell LH (2004) Public perception of the terms "cosmetic," "plastic," and "reconstructive" surgery. Arch Facial Plast Surg 6: 315-320.

10 Lau CK, Schumacher HH, Irwin MS (2010) Patients' perception of medical photography. J Plast Reconstr Aesthet Surg 63: e507-e511.
11 Galdino GM, DaSilva D, Gunter JP (2002) Digital photography for rhinoplasty. Plast Reconstr Surg 109: 1421-1434.

12 Galdino GM, Vogel JE, Vander Kolk CA (2001) Standardizing digital photography: it's not all in the eye of the beholder. Plast Reconstr Surg 108: 1334-1344.

13 Gherardini G, Matarasso A, Serure AS, Toledo LS, DiBernardo BE (1997) Standardization in photography for body contour surgery and suction-assisted lipectomy. Plast Reconstr Surg 100: 227-237.

14 Henderson JL, Larrabee WFJ, Krieger BD (2005) Photographic standards for facial plastic surgery. Arch Facial Plast Surg 7: 331-333.

15 Jemec Bl, Jemec GB (1986) Photographic surgery: standards in clinical photography. Aesthetic Plast Surg 10: 177-180.

16 Parker WL, Czerwinski M, Sinno H, Loizides P, Lee C (2007) Objective interpretation of surgical outcomes: is there a need for standardizing digital images in the plastic surgery literature? Plast Reconstr Surg 120: $1419-1423$.

17 Sommer DD (2004) Mendelsohn M. Pitfalls of non-standardized photography in facial plastic surgery patients. Plast Reconstr Surg 114: 10-14.

18 Neff LL, Humphrey CD, Kriet JD (2000) Setting up a medical portrait studio. Facial Past Surg Clin N Am 18: 231-236.

19 Riml S, Piontke AT, Larcher L, Kompatscher P (2010) Widespread Disregard of Photographic Documentation Standards in Plastic Surgery: A Brief Survey. Plast Reconstr Surg 126: 274e-276e.

20 Riml S, Piontke A, Larcher L, Kompatscher P (2011) Quantification of faults resulting from disregard of standardised facial photography. J Plast Reconstr Aesthetic Surg 64: 898-901. 